\title{
ON THE GENUS OF THE CO-ANNIHILATING GRAPH OF COMMUTATIVE RINGS
}

\author{
K. Selvakumar and S. Karthik \\ Department of Mathematics \\ Manonmaniam Sundaranar University \\ Abishekapatti, Tirunelveli 627 012, Tamil Nadu, India \\ e-mail: selva_158@yahoo.co.in \\ skarthikmat91@gmail.com
}

\begin{abstract}
Let $R$ be a commutative ring with identity and $\mathfrak{U}_{R}$ be the set of all nonzero non-units of $R$. The co-annihilating graph of $R$, denoted by $\mathcal{C} \mathcal{A}_{R}$, is a graph with vertex set $\mathfrak{U}_{R}$ and two vertices $x$ and $y$ are adjacent whenever $\operatorname{ann}(x) \bigcap \operatorname{ann}(y)=(0)$. In this paper, we characterize all commutative Artinian non-local rings $R$ for which the $\mathcal{C} \mathcal{A}_{R}$ has genus one and two. Also we characterize all commutative Artinian non-local rings $R$ for which $\mathcal{C} \mathcal{A}_{R}$ has crosscap one. Finally, we characterize all finite commutative non-local rings for which $g\left(\Gamma_{2}(R)\right)=g\left(\mathcal{C} \mathcal{A}_{R}\right)=0$ or 1 .
\end{abstract}

Keywords: co-annihilating graph, planar graph, genus; crosscap.

2010 Mathematics Subject Classification: 13A15, 05C75.

\section{REFERENCES}

[1] S. Akbari, H.R. Maimani and S. Yassemi, When a zero-divisor graph is planar or a complete r-partite graph, J. Algebra 270 (2003) 169-180. doi:10.1016/S0021-8693(03)00370-3

[2] J. Amjadi and A. Alilou, The co-annihilating graph of a commutative ring, Discrete Math. Alg. and Appl. 10 (1) (2018) 1850013(1-12).

doi:10.1142/S1793830918500131

[3] S. Akbari, J. Amjadi, A. Alilou and S.M. Sheikholeslami, The co-annihilating ideal graphs of a commutative ring, Canad. Math. Bull. 60 (2017) 3-11. doi:10.4153/CMB-2016-017-1

[4] S. Akbari, M. Habibi, A. Majidinya and R. Manaviyat, A note on comaximal graph of non-commutative Rings, Algebr. Reprsent. Theory 16 (2013) 303-307. doi:10.1007/s10468-011-9309-z 
[5] D.F. Anderson and P.S. Livingston, The zero-divisor graph of a commutative ring, J. Algebra 217 (1999) 434-447. doi:10.1006/jabr.1998.7840

[6] M.F. Atiyah and I.G. Macdonald, Introduction to Commutative Algebra (AddisonWesley Publishing Company, Londan, 1969).

[7] A. Badawi, On the annihilator graph of a commutative ring, Comm. Algebra 42 (2014) 108-121. doi:10.1080/00927872.2012.707262

[8] M. Behboodi and Z. Rakeei, The annihilating-ideal graph of commutative rings-I, J. Algebra Appl. 10 (2011) 741-753. doi:10.1142/S0219498811004902

[9] R. Belshoff and J. Chapman, Planar zero-divisor graphs, J. Algebra 316 (2007) 471-480. doi:10.1016/j.jalgebra.2007.01.049

[10] G. Chartrand and P. Zhang, A First Course in Graph Theory (Dover Publications, Mineola, NY, USA, 2012).

[11] Hung-Jen and Chiang-Hsieh, Classification of rings with projective zero-divisor graphs, J. Algebra 319 (2008) 2789-2802. doi:10.1016/j.jalgebra.2007.10.015

[12] M. Bojan and T. Carsten, Graphs on Surfaces (John Hopkins University Press, Baltimore, 2001).

[13] N. Bloomfield and C. Wickham, Classification of rings with genus two zero-divisor graphs, Comm. Algebra 33 (2010) 2965-2980. doi:10.1080/00927870903100093

[14] K. Selvakumar and M. Subajini, Crosscap of the non-cyclic graph of groups, AKCE Inter. J. Graphs and Combin. 13 (2016) 235-240. doi:10.1016/j.akcej.2016.06.013

[15] H.J. Wang, Zero-divisor graphs of genus one, J. Algebra 304 (2006) 666-678. doi:10.1016/j.jalgebra.2006.01.057

[16] H.J. Wang, Graphs associated to co-maximal ideals of commutative rings, J. Algebra 320 (2008) 2917-2933. doi:10.1016/j.jalgebra.2008.04.013

[17] H.J. Wang, Co-maximal graph of non-commutative rings, Linear Algebra Appl. 430 (2009) 633-641. doi:10.1016/j.laa.2008.09.022

[18] A.T. White, Graphs, Groups and Surfaces (North-Holland Publishing Company, Amsterdam, 1973).

[19] C. Wickham, Classification of rings with genus one zero-divisor graphs, Comm. Algebra 36 (2008) 325-345. doi:10.1080/00927870701713089

Received 1 December 2018

Revised 5 June 2019

Accepted 18 June 2019 